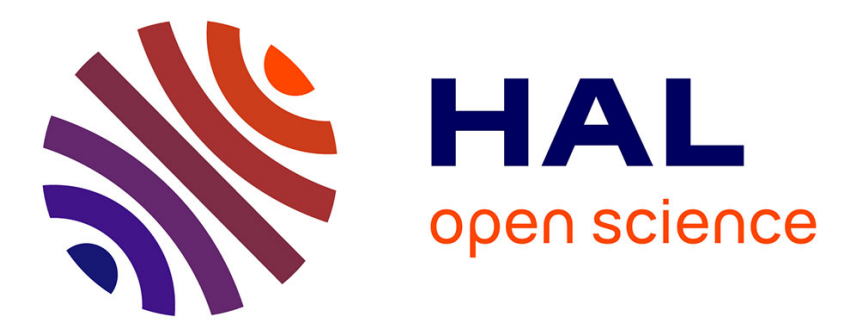

\title{
Anaphora: lexico-textual structure, or means for utterance integration within a discourse? A critique of the Functional Grammar account
}

Francis Cornish

\section{- To cite this version:}

Francis Cornish. Anaphora: lexico-textual structure, or means for utterance integration within a discourse? A critique of the Functional Grammar account. Linguistics, 2002, 40 (3), pp.469-493. hal-00967224

\section{HAL Id: hal-00967224 \\ https://hal-univ-tlse2.archives-ouvertes.fr/hal-00967224}

Submitted on 28 Mar 2014

HAL is a multi-disciplinary open access archive for the deposit and dissemination of scientific research documents, whether they are published or not. The documents may come from teaching and research institutions in France or abroad, or from public or private research centers.
L'archive ouverte pluridisciplinaire HAL, est destinée au dépôt et à la diffusion de documents scientifiques de niveau recherche, publiés ou non, émanant des établissements d'enseignement et de recherche français ou étrangers, des laboratoires publics ou privés. 


\title{
Anaphora: lexico-textual structure, or means for utterance integration within a discourse? A critique of the Functional Grammar account ${ }^{1}$
}

(Linguistics 40 (3), June 2002, pp. 469-493)

\author{
Francis Cornish, CNRS UMR 5610 and Université de Toulouse-Le Mirail, \\ France
}

\begin{abstract}
This article is a critical examination of Dik's (1997b: ch. 10) account of discourse anaphora, within the framework of the theory of Functional Grammar (but it highlights features of anaphora theory which hold more generally). I show first that Dik's definitions of the phenomenon involve two contradictory conceptions of this discourse procedure (the anaphor refers to a mental representation of its referent within a mental model of the ongoing discourse, yet at the same time needs first to connect up with a segment of co-text - its linguistic antecedent); second, that Dik's account of the relationship between given (pronominal) anaphor types and the "entity-order" of their potential referents is both too rigid and too narrow; and third, that his description of the underlying structure of anaphors, which includes both the referential index of their actual referent/antecedent and a variable specifying the latter's entity-order, does not allow for the necessary flexibility and dynamic character of anaphor use and interpretation. A discursively more realistic account of discourse anaphora needs to specify the necessary interaction between 'bottom-up' factors of these kinds, on the one hand, and 'top-down' relationships involving the wider discourse context, on the other. This is what I briefly outline at the end of the article.
\end{abstract}

\section{Introduction}

In the most recent two-volume presentation of the standard theory of Dikian Functional Grammar, Dik (1997b) devotes a whole chapter to anaphora (both sentence and discourse anaphora) (ch. 10), and a further chapter to an outline of an approach to discourse (ch. 18). Anaphora figures prominently throughout the current development of Functional Grammar (henceforth FG) as a whole - for example, in its account of relative clauses, and in its definitions of the variables marking each of the different layers within underlying clause structure: indeed, the possibility of distinctive anaphoric reference to each of these layers provides important evidence in favour of their independence. The opening up of the originally clause-bound model to discourse which is now being undertaken is developing in parallel with a concern for anaphora ${ }^{2}$. This is only natural, since anaphora and deixis at the discourse level are an important means of coordinating the attention of the discourse participants, as well as of converting text into discourse (and vice versa from the speaker's point of view, of course).

This is why I think now is a good time to examine the current (still programmatic) FG approach to anaphora, as set forth in Dik (1997b: ch. 10), 
and to see to what extent it can be situated within what is now known about discourse and anaphora generally. I will discuss three basic issues raised by Dik's account, and which may be seen to be relevant generally, whatever the approach to anaphora and reference in discourse. These are as follows:

1) The very fundamental question of the nature of the anaphoric relation (i.e. whether it is necessarily mediated by the prior mention (that is, "use") of an antecedent expression in the co-text or not);

2) The relation between the form of an anaphor and the potential entity-order(s) of its referent; and

3) The formalism used by Dik to represent anaphors in underlying clause structure, and the (necessarily) dynamic relationship between anaphors, their containing predication, and the utterance containing a relevant "antecedent-trigger".

We shall see that these three issues are closely linked. In what follows, I devote a section (respectively, sections 2, 3 and 4) to each of these basic questions.

\section{The current FG view of anaphora}

Dik (1997b: ch. 10) rightly distinguishes between "the underlying anaphorical (sic) relation" and "its formal expression" (p. 215). He then attempts to define well-formedness conditions for anaphora in functional terms. Dik gives what I would argue are two different definitions of anaphora, cited below as Definitions I and II, respectively.

\section{Anaphora : Dik's (1997b: 215) Definition I}

"I speak of anaphora as occurring when an element of underlying clause structure refers to an entity which has already been established, directly or indirectly, in the preceding discourse (discourse anaphora) or is being established in the same clause (sentence anaphora)."

\section{Anaphora : Dik's (1997b: 216) Definition II}

"...The expression with which the entity in question [i.e. the referent] has been or is being established in the discourse is the antecedent of the anaphorical (sic) element. (...) The relation between anaphoric element and antecedent will be called an anaphorical relation.".

I view these definitions as involving two distinct conceptions of the anaphoric relation involved here: in the first (Definition I), the anaphor refers to an entity (or more accurately, to the mental representation of an entity as 
evoked via the preceding discourse) which is already established in the addressee's discourse model - this is what would most commonly be called nowadays a discourse referent; but in the second conception (Definition II), the relata involved are the antecedent (a co-occurring linguistic expression) and the anaphor.

In Dik's Principle (ii) (p. 215), he states that "All anaphors have an antecedent in the discourse. The antecedent itself is not used anaphorically, but it serves to establish some entity in the discourse."

Before we proceed any further, I think we need a definition of the notions of text and discourse. This is given under (1) below.

\section{(1) Text vs. discourse}

Text denotes the connected sequence of verbal signs and non-verbal signals in terms of which discourse is co-constructed by the participants in the act of communication.

Discourse denotes the hierarchically structured, situated sequence of utterance and illocutionary acts carried out in pursuance of some communicative goal, as integrated within a given context.

The context is subject to an ongoing process of construction and revision as the discourse unfolds. (My definitions - FC; see Cornish, 1999: subsection 2.3 for further development and illustration of this distinction, and its importance for the study of discourse anaphora).

Text, then, is the tangible, perceptible record of at least one utterance act (whether realised in terms of a verbal, linguistic trace or of a non-verbal trace which may be gestural, sensory-perceptual or prosodic). The discourse partners make use of this record, in conjunction with their invocation of a relevant context, in order to create discourse. The distinction is close to that drawn recently within an FG context by van den Berg (1998) between the concepts of utterance and message (structure), and in a "text worlds" context by Werth (1999: 46, 302) $)^{3}$. So when Dik says that "all anaphors have an antecedent in the discourse", he no doubt means "text". His Definition I, on the other hand, is framed within the context of "discourse" (according to my definition (1)).

Under Dik's conception of anaphora, it is necessary for there to be a previous mention in the surrounding co-text of the entity referred to by an anaphor, and it is this mention which constitutes the antecedent (i.e. a linguistic expression used in the co-text of some anaphor).

But prior mention is in reality neither a necessary nor a sufficient condition for the existence of anaphora - as indeed Dik himself suggests in formulating his first conception of anaphora (Definition I above), when he writes that "an element of underlying clause structure refers to an entity which has already been established, directly or indirectly, in the previous discourse" (my emphasis). If we take discourse seriously, as Dik claims to do (particularly 
in his chapter 18 devoted to this topic), then it is clear that naturally-occurring discourse ${ }^{1}$ is full of instances where there exists a mutually assumed discourse referent which is retrieved by a given anaphor, without that referent having been explicitly introduced into the discourse by a prior mention.

Let us look at the examples under (2) below. In order to be felicitous (i.e. coherent), these instances of implicit or indirect anaphora all require that some kind of connection be available for the addressee to be able to retrieve the correct, intended referent.

(2) a [Context: a neighbour's father has been in hospital for a week already] Anne to her neighbour, seeing her looking haggard: How is he?

(2a) trades on the existence of certain specific prior knowledge shared by the interactants (in their episodic memories). We may assume that the subject of the neighbour's father's health has been intensely discussed over the past days, and so is constantly at the forefront of the neighbours' consciousness. The trigger of that discourse domain is Anne's seeing her neighbour looking haggard and immediately realising the reason for it.

(2) b The high street bank on the corner has been broken into twice this month. But they only took the small change.

[they $=$ 'the bank-robbers']

In $(2 b)$, it is the stereotypical knowledge frame evoked via the initial sentence (a bank break-in), making available a slot for the perpetrators of the act, which motivates the indirect anaphoric reference: the default reference realised via the type, "indefinite" pronoun they. The speaker cannot assume that the addressee has any particular individuals in mind at the point of use; but their non-specific existence is nonetheless assumed.

(2) c [Context : Mary and Barbara are discussing Sarah, who Mary knows well but who Barbara has only met once]

Mary: She's always so good-humoured, you know ...but HE's a bore.. $[\boldsymbol{H E}=$ 'Sarah's husband/partner']

In (2c), there is obviously an abductive, or backward-looking inference needed to instantiate (i.e. accommodate) a referent not hitherto presupposed to exist. The reference of $\boldsymbol{H E}$ here is deictic (or anaphorico-deictic), not strictly anaphoric: a contrastive pitch-accent on this pronoun is required in order for the reference to have any chance of succeeding. The focus structure applied to the predicative content of the two clauses clearly indicates a contrast between

1 For example, conversations, interviews, meetings, letters, sports commentaries, and so on 
the personalities of the two individuals concerned, both pronouns occurring in parallel subject position in their respective clauses. This use also trades on the assumption of the addressee's knowledge of a "frame" - here, that of the "couple" - in order to introduce a representation of Sarah's partner into the addressee's discourse model.

(2) d [Context: a young goat wanders through the open front door] A to B, observing the event in fascination: What do you think it's looking for?

In (2d), the key factor in the exophoric use of the pronoun is the co-presence of the referent in the situational context, and the fact that the discourse partners are focussing on this unexpected event which is immediately attracting their attention.

(2) e [Context : Woman returning from country walk where she had intended to pick blackberries. Local retired man sitting on log observing her walk back with empty box]

Man : So you didn't find any $\emptyset$, then?

Finally, (2e) trades upon a forward-looking inference based on the man's observation of the scene, and on his knowledge of the common plans of action as well as motivations which people in society typically have.

Apart from (2c) where the reference is deictic (or anaphorico-deictic), all these instances are cases of anaphora, where the anaphor is intended to pick up a representation of a referent assumed by the speaker to be accessible and salient to the addressee at the point in the discourse where that anaphor occurs. But in no case is there a prior explicit "mention" of the intended referent. Note that in all types of anaphora, there is a (semantic/pragmatic) connection of one kind or other between what I call the antecedent trigger ${ }^{2}$ and a relevant salient discourse representation. In discourse anaphora, the antecedent trigger is an utterance token, a gesture or percept which evokes or boosts a given mental representation of a state of affairs (SoA) into speaker's and addressee's current discourse models.

One other very important factor in the operation of anaphora is the nature of the anaphoric predication ${ }^{3}$ : that is, what is predicated of the referent of the anaphor (which may still be unascertainable at the point when it is uttered) acts as a pointer towards a referent of a certain type; in other words, it places a

\footnotetext{
2 See Cornish (1999:\$2.4.1) for justification for and illustration of this construct.

3 Cornish (1999: ch.3) examines in detail various key aspects of this predication (termed there the indexical segment) and their role in the functioning of anaphora.
} 
semantico-pragmatic constraint on its potential values. A pair of examples presented in Wilson (1992) makes the point very clearly:

(3) a Sean Penn attacked a photographer. The man was quite badly hurt.

b Sean Penn attacked a photographer. The man must be deranged.

Here, each anaphoric predication most naturally continues the perspective involving a different discourse referent mutually available to the speech partners at the point where the definite subject NP of the second sentence occurs - a term which is semantically appropriate for retrieving either of these referents. Note, though, that if we replace these two occurrences of the man by the pronoun $h e$, the first but not the second becomes slightly unnatural. This is due to the preference for subjects, but not non-subjects, to be construed as topics, as well as to the restriction of unaccented third person pronouns to referents which are highly discourse-active. However, (4) below shows that the anaphoric predication does not always perform an orienting function with regard to the choice of a suitable referent for the anaphor ${ }^{4}$ :

(4) Mary $_{i}$ told Jane $e_{j}$ that she ilj $_{j}$ would have to see a doctor.

In all these examples, the anaphoric predication continues one aspect of the mental scene evoked via the context. So it seems, on the basis of an observation of real discourse in specific contexts of utterance (as opposed to careful, invented one- or two-sentence examples where there is an explicit prior mention of the intended referent), that prior mention is but one way in which a given referent may enter the addressee's discourse model, justifying its later re-accessing via an appropriate anaphor.

Prior mention is of course normatively required in careful written genres of discourse, and linguists studying anaphora have in the past tended to base their analyses on invented mini-texts which have a definitely "written" feel about them. But are we justified in extrapolating from normative, written prose to the entire range of discourse in characterising the anaphoric relation? In my view, we are not, and the observation of a wide range of discourse genres ${ }^{5}$ seems to suggest a rather different model of anaphora from the traditional one whereby an anaphor (typically a pronoun of some kind) has first to be paired

\footnotetext{
Note however the slight difference in the sense of the matrix verb told under each interpretation of the out-of-context ambiguous pronoun she in (4): where the NP Mary is understood as being coreferential with she, it has the sense "informed"; but where the NP Jane is coreferential with the pronoun, told has a value close to "ordered", "enjoined" (as in Mary told Jane to see a doctor, where only the second of the two interpretations indicated above is possible, the anaphor being the zero 'subject' of see a doctor).

$5 \quad$ See McCawley (1991), Oakhill \& Garnham (1992), and Cornish (1997) for presentations and analyses of corpora of attested utterances from a range of genres and registers, in connection with an account of discourse anaphora.
} 
with a co-occurring antecedent expression to enable its full sense and reference values to be instantiated.

There is, then, a tension, it seems to me, between the two conceptions of anaphora (reference via an "antecedent expression" available in the co-text, and reference in terms of a discourse representation of an entity of some kind) which Dik simultaneously entertains. And on p. 220, Dik states that "the form of the anaphoric element varies according as the antecedent entity is a first-order entity, a second-order SoA, or a propositional content" (my emphasis). Here, it seems, the two conceptions of anaphora distinguished earlier are conflated into a single weave, with the concept of "antecedent entity". Dik is guilty of a similar confusion as well as of contravening his own principle (i) ( $\mathrm{p}, 217)$, namely that "the anaphor does not refer to the antecedent", in saying on p. 228: "In all these cases, the anaphorical element refers to an antecedent which is a full speech act". Anaphors can of course refer to speech acts, but a speech act is not an antecedent (i.e. an "expression", in Dik's sense). Dik's (traditional) conception of the antecedent further loses its force when he notes the possibility of an anaphor referring to a sub-topic inferable from the entity introduced by the "antecedent", as in the examples of "associative anaphora" he presents:

\section{(5) a On a bench in a park he saw an elderly couple. The man....The woman... \\ b John bought a book, but after reading the first few pages he threw it away. (Dik, 1997b: exs. (2a,b), ch.10)}

Here, the notion of antecedent-trigger would seem more appropriate to characterise the role of the NPs an elderly couple and the book: that is, as introducing into a discourse a number of entities which may later be retrieved via an appropriate anaphor.

The fact (specifically highlighted by Dik in his discussion of the various types of anaphoric expression and their discourse-pragmatic roles: cf. § 10.3.1 "Pragmatic factors") that each separate sub-type of anaphor bears a distinctive bundle of semantic and referential properties means that they are not simply the passive recipient of a sense and reference assigned derivatively by a lexically fuller co-occurring expression (the antecedent); instead, they are actively responsible for the accessing of a referent or a denotation which has certain consequences both for the current interpretation of the wider discourse segment in which antecedent-trigger and anaphoric predication co-occur, and for the subsequent direction of the discourse to follow.

The notion of antecedent expression is also perhaps motivated by the convenience (in evidence since the advent of TG) of annotating linguistic segments in an example for same or different indices (marking coreference vs. non-coreference). But as pointed out by Lambrecht (1994) in connection with 
the similar annotating of linguistic segments in terms of their Topic or Focus functions, this is not always either feasible or perspicuous.

\section{Anaphor type and entity-order}

Dik's major concern within the body of the chapter, though, is with the entity order types of referent which an anaphor may have - thus with the first conception of anaphora mentioned earlier. Indeed, he is concerned here not with the linguistic identity of segments (antecedent segment in the co-text and the segment corresponding to the anaphor), but with the various forms of the anaphors concerned in relation to the ontological (and discourse) status of the referents of those anaphors.

Two parameters determine the use of a particular anaphor type in a discourse. They are (a) the functioning of the anaphor with respect to the discourse status of its intended referent, assumed already to be present in that discourse - the formation of different "chains" of anaphors (definite or demonstrative NPs, pronouns of different types: definite ordinary pronouns, demonstrative pronouns (this vs. that), zeros, etc.) according as the status of the referent is foregrounded or backgrounded at the stage which the discourse has reached when the anaphor is used ${ }^{6}$. And (b) the ontological nature (in terms of entity-order) of the referent assumed by the use of particular types of anaphors (only pronouns are discussed in this context).

But in this latter respect, is there really a one-to-one relationship between type of pronoun and type of entity-order of its assumed referent, as Dik implies there is? That is, one $=$ 'property $\left(\mathrm{f}_{\mathrm{i}}\right)^{77}$, him/her/it $=$ 'spatial entity $\left(\mathrm{x}_{\mathrm{i}}\right)^{\text {' }}$, the $X$-ing (where $\mathrm{X}$ is a verb), or, presumably, it/that, = 'SoA $\left(\mathrm{e}_{\mathrm{i}}\right)$ ', so = 'possible

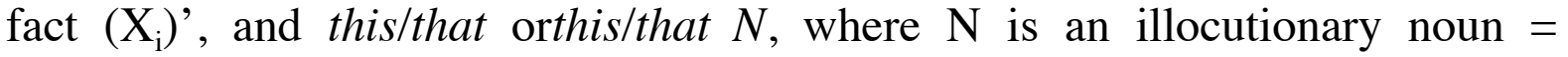
'illocution (or perlocution) $\left(\mathrm{E}_{\mathrm{i}}\right)$ '. Presumably, the pronoun there would be given Mackenzie's (1992) ' $p$ ' variable (for 'place'), and then 't', for 'time'. Dik (1997b: 220) is a bit too rigid, to my mind, on the relationship (which he sees as fixed) between given anaphor types and given entity-order denotations ${ }^{8}$ : for while the personal pronouns he/she/they and their variant forms do indeed have first-order referents, the pronoun it may refer to a range of entity types, in addition to the second-order SoA illustrated in his example (12b):

6 See Cornish (1998) for a discussion of Dik's conception of the structure of "anaphoric chains" in discourse, and the analysis of a short English newspaper article in terms of it.

7 Personally, I think 'type' is a better characterisation of the potential denotations of one.

8 This is in essence the same point that Liedtke (1998:111) makes in connection with Dik's view of the relationship between sentence form (mood types: declarative, interrogative, imperative and exclamative) and type of illocutionary force (assertion/statement, question, command, exclamation), Dik assuming a direct, one-to-one correlation between the various mood or sentence types, on the one hand, and the respective illocutionary force types, on the other. As analogously in the case of the relation between pronoun form-types and entity-order types, Liedtke argues in favour of a much looser, non-deterministic relation between sentence form-types and the potential illocutionary forces which they may be used to express. 
(6) John saw [Bill win $]_{i}$ and Peter saw it ${ }_{i} /$ that $_{i}$ too. (Dik's annotations)

It may have a first-order referent (either inanimate as in 'the table', or animate: animals, insects etc., plants...or even human: babies). But it can also have third order referents (propositional contents):

(7) Jack said he’d just won $£ 30,000$ on the lottery, though Mary didn’t believe it. (My example)

In some cases, it may have a Ø-order 'property' referent. This depends largely on the type of host verb (in (8), it is verbs of appearance which are illustrated) which acts as predicator in the anaphoric clause:

(8) Mary said she felt weak and ill. She certainly \{looked/sounded\} it.

This and other examples shows that the type of entity order denoted by a given anaphor is only a preference: it can be overridden by various properties of the anaphoric predication as a whole, amongst other factors, particularly by those of the host predicator.

The pronoun so can also have as referent other entity-order types than the propositional content one claimed to be the case by Dik, and which he illustrated in his example (12c):

(9) John thought that [Bill would win $]_{i}$ and Peter thought so $o_{i}$ too .

It may denote a manner, as in the proclitic occurrences so-arranged, so-called, etc. See also the indefinite determiner such. I would say that so retrieves intensional 'type' referents (nonpresupposed propositional contents), whereas it prototypically has as potential referents ones which have extensionality, or are propositions that have been mutually validated by the discourse partners: they can be treated as (actual) facts for the purposes of the ensuing discourse, not as "possible facts", which is, I believe, why Dik considers so to have this kind of reference. So is indefinite and intensional (and not fully nominal, rather it is adverbial), whereas it is both definite and extensional, as well as being fully nominal in character (see Cornish, 1992 for further evidence in favour of these analyses).

The distal demonstrative pronoun that can refer to four of the five types of entity order isolated by Dik: entity order 1 (inanimate entities), as in (10B):

(10) A: I'm going to cook cous-cous tonight.

B: Really? I've never liked that. 
Entity order 2 (SoAs):

(11) [Child puts hand near flames coming from coal fire] Parent: Johnny, don't DO that!

Entity order 3: Propositional content:

(12) A: Did you see in the paper that the prime minister has called a General Election for next month?

B: What? I didn't know that/That's incredible!

Entity order 4: Illocutions (and potentially also, perlocutions):

(13) Mother-in-law to daughter-in-law :We're coming to visit you next Sunday. Daughter-in-law (jokingly): Is that a threat or a promise?!

Distal that, unlike its proximal counterpart, has a preference for use in negative, distancing contexts, or where the referent is conceived as a hypothetical, not an actual, object or situation. It also has (due to its demonstrative character) a definite focussing effect in relation to it, its unaccented counterpart. Its proximal counterpart this, which has exactly the same range of denotation types as that, can be used to encapsulate a whole segment of discourse and to treat it as a compacted entity which is to be the topic of a new discourse segment.

It is, in the last analysis, the properties of the anaphoric predication which determine the actual entity order of the pronoun's referent. First and foremost among these is the nature of the host predicator. That is, verb of cognition or propositional attitude (e.g. believe) + it --> ' $\mathrm{X}_{\mathrm{i}}$ '; activity verb (e.g. do $)+i t$ $-->$ ' $\mathrm{e}_{\mathrm{i}}$ '; appearance verb (e.g. look) + it $-->{ }^{\prime} \mathrm{f}_{\mathrm{i}}$ '; It + illocutionary predicator (e.g. be a lie/threat) --> ' $\mathrm{E}_{\mathrm{i}}$ '. Note that, where a sub-class of propositional attitude verbs (such as guess, imagine, know) is constructed with so as propositional anaphor rather than with it, the semantic status of the verb changes: it no longer has its full lexical sense, but takes on a parenthetical, non-assertive semantic value whereby the speaker withholds a full commitment to the truth of the proposition accessed via the pronoun (see Cornish, 1992 for fuller discussion of this issue).

\section{The formalism used by Dik to represent anaphors, and the three-way relationship between anaphor type, anaphoric predication, and discourse context}

The formalism which Dik adopts in representing the underlying structure of anaphors is problematic. Anaphors are indexicals: language-particular 
form-types, each of which possesses a specific set of semantico-referential properties. Where pronominal in character, they encode values in respect of the categories of person, number, gender, case, definiteness as well as features like 'already categorised' vs. 'not categorised/uncategorisable' - a value coded by the neuter pronouns in particular, in languages such as French, German, Spanish and those from the Slavic family. These properties derive from the language system, and so may legitimately be claimed to be included in underlying clause representations (where a given anaphor has been selected from the Lexicon together with its term frame structure).

But Dik also represents in the structures underlying anaphors (a) the variable symbolising the entity order of their actual referent, and (b) the index of that referent as encoded in a co-occurring underlying clause structure (presumably where there is no syntactic, semantic or pragmatic restriction inhibiting this relationship). (14) provides a sample of Dik's representations of anaphors.

(14) Dik's (1997b: ch. 10) underlying representations of a sample of anaphors

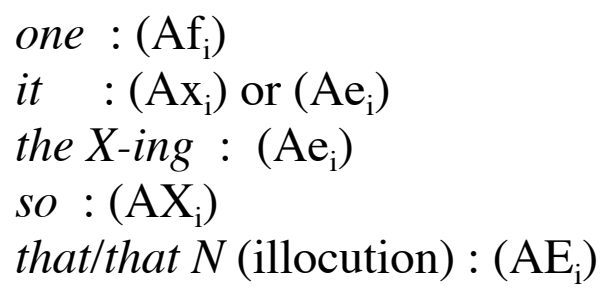

(15) presents a sample representation of an underlying two-clause mini-text, where an anaphor (here so) is resolved.

(15) Representation of example (9) (simplified)

think (John) $\left(\mathrm{X}_{\mathrm{i}}:[\right.$ Bill would win $\left.]\right)$ and

think (Peter) $\left(\mathrm{AX}_{\mathrm{i}}\right)$ too (Dik, 1997b, ch. 10, ex. (33))

But, with the exception of pronoun types such as one and the third-person personal pronouns, which unambiguously encode a particular entity-order type of denotation, these potential features of a given anaphor are not system-determined (unlike the grammatical features mentioned a moment ago); instead, they are discourse-determined. There must therefore be a meshing between the output of the rules governing the construction of underlying clause structures, on the one hand, and the effect of the principles, tendencies etc. which regulate the construction of discourse, on the other - contextual reference 
being clearly part of the latter ${ }^{9}$. In the case of entity-order type denotation, as we saw earlier, the range of entity orders which a given anaphor may have is constrained, not wholly by rules of clause structure (as Dik's representations seem to assume), but also, and mainly, by principles of discourse structure framed within the meta-principle of interpretative coherence.

This may be seen in examples like $(3 a, b)$ above, where the same anaphoric form (the man) was able to have two different referents evoked via an identical antecedent-trigger predication (the initial sentences of each example) depending on which one was the target of a predication by the anaphoric clause as a whole (that is, in (3a), "having been quite badly hurt (in the circumstances previously evoked)", and in (3b), "needing to be deranged (to have done such a thing)"). We cannot begin to know what the actual referent of a given anaphor might be until we have access to the discourse as well as to its context. That is, to determine a given anaphor's intended referent, we need to take discourse pragmatics on board. ${ }^{10}$ The contradiction which I raised in section 2 of this article between the conception of anaphora as involving a quasi-grammatical correlation between an antecedent expression in surrounding discourse and an anaphor (a relationship manifested in the sharing of indices between the two expressions), and the view of anaphora as involving the retrieval of a salient discourse representation encoded in the discourse partners' current discourse model, makes itself felt here. In fact, the coindexing device used by Dik is only feasible where there is a candidate antecedent expression in the surrounding co-text. Where there is not - as in the cases of exophora illustrated in (2a,b,d and e), which I would argue are the basic instances of anaphora -, this device is totally inoperative, the relationship here being of necessity between a salient discourse representation and an anaphoric expression, and not between two isolatable co-occurring expressions.

The index of a given referent (whether it be an argument, a predicate, predication, proposition or clause) should not, in my view, already be marked as

\footnotetext{
9 Others have argued in favour of a "division of labour" between pragmatic principles which are separate from the clause grammar (and which deal with such phenomena as topic-focus assignment and illocutionary force specification, and which have a determining influence on grammatical coding), and the grammatical rules and constraints which govern morpho-syntactic form, the province of a "grammatical module" (see in particular Van den Berg, 1998, for an elaboration of such a framework which takes account of the specifics of the FG model of grammar).

10 At the presentation of the paper on which this article is based, Co Vet suggested that since FG clause derivations are production-oriented (that is, object-language expressions are derived from the speaker's point of view), it is natural that co-indexing for coreference should be marked in underlying clause structures; after all, the speaker usually knows in advance whether or not a given anaphor corefers with some other clausal constituent. This is no doubt true. However, I believe it is largely irrelevant in the context of discourse, since at this level, a speaker, in order successfully to refer, has to get his addressee to establish the intended reference (or the intended correlation between two or more identical acts of reference in the case of anaphors); that is, reference is a cooperative affair, not something carried out by only one of the discourse partners. In addition, even if the speaker were conceivable as an autonomous, independent discourse agent (which I do not believe he could be), it is still the case that his acts of reference only take place dynamically, in a discourse context. They could not be accounted for already within the Lexicon, i.e. hors usage.
} 
such in the representation of the anaphoric term, as Dik maintains it should be. After all, in the case of discourse anaphora, coreference or non-coreference is not something which is automatically assigned, as it may well be in grammaticalised instances of anaphora (sentence anaphora): for example, in infinitival subject control, relative clauses, reflexive predications, and so on. Here, the choice of index (i.e. co-referent) for a given anaphor is more or less fully determined by the syntactico-predicative context in which the anaphor occurs. I therefore believe that this index should not be specified in anaphoric terms at the level of the clause realisation: a given anaphor is selected with its term structure frame directly from the Lexicon, where of course no indication of its actual reference can possibly be marked. This occurs only when the text constituted by a clause structure (in combination with surrounding clause structures) is converted into discourse by being integrated with a context. It should be left up to the (as yet unspecified) discourse component or domain of the model to provide heuristics for specifying the index (but see the tentative suggestions at the end of this section as to how this might be done).

(16) below is an attempt to give more detailed specifications of the structures underlying given anaphor types (as contained in the Lexicon).

(16) Proposal for revision of method of representing the structure underlying anaphors (prior to their discourse resolution) in FG

$$
\begin{aligned}
& \text { it }:(\mathrm{d} 1 \mathrm{A \alpha}:<\text { inanimate }>(\alpha)) \\
& \text { so }:(\mathrm{i} \mathrm{Af} / \mathrm{X}:<\text { intensional }>(\mathrm{f} / \mathrm{X})) \\
& \text { that }:(\operatorname{dist} \mathrm{A} \alpha:<\text { inanimate }>(\alpha)) \\
& \text { he }:(\mathrm{d} 1 \mathrm{Ax}:<\text { human }>\&<\text { male> }>(\mathrm{x})) \\
& \text { they }:(\mathrm{d} / \mathrm{i} \mathrm{m} \mathrm{Ax}:<\operatorname{set}>(\mathrm{x}))
\end{aligned}
$$

The 'A' symbol (designating an anaphoric predicate) constitutes an instruction to the addressee to look for a prior discourse entity whose representation can match the features already specified in the anaphor. Particularly important here is the selection restriction imposed on a potential referent for the anaphor (see Cornish, 1999:§3.2.2 for some discussion). That is, the referent (which is not automatically yielded by the anaphor qua (potentially) referring expression) is viewed as an argument to the essentially predicative conditions contained within the anaphor. As in the case of a canonical predicate, the selection restriction carried by a given anaphor type constrains the possible choice of an argument/referent which will 'saturate' it, thereby giving rise to a potential secondary reference, just as the saturation of a predicate by one or more arguments gives rise to a potential predication. The ' $\alpha$ ' variable in the representations of the pronouns it and that ranges over the five entity-order types recognised so far in FG (as already indicated, however, we need to make allowance for more than this number). 
Under this conception of anaphor resolution, then, there are three distinct stages in the process (see also the algorithms for discourse anaphor resolution presented, for example, in Asher \& Wada, 1988, and in Walker, 1998):

1. A given anaphor type is selected from the Lexicon to fill the argument position of a predicator, and an anaphoric clause is formed.

2. A 'co-composition' (Pustejovsky, 1995) process is triggered, whereby certain relevant properties of the anaphoric clause as a whole are combined: the semantic class of the predicator assigns a denotational category to the anaphor, the predicator and its "internal" argument(s) are combined, then the output of this combination is integrated with the clause's referential features (its aspect, tense, mood and modality assignments). These features collectively assign an entity order type to the anaphor. See Cornish (1999: ch.3) for some development of these relationships.

Where this is not already specified unambiguously (as in the case of this/that, it, so, etc.), then the entity-order type is filled in contextually.

Where it clashes with a specific entity-order type already contributed by the anaphor (as potentially in the case of the personal pronouns he/she/they, as well as one), anomaly is predicted.

Where it matches this value, then the resolution process may continue.

Where there is a small range of entity-order types already contributed by the anaphor (as in the case of so, for example - see (16)), then the anaphoric predication as a whole will be able to select the one conforming to the entity-order type which it compositionally specifies.

This general process is very similar to the way in which the selection restrictions of a predicate operate in the standard theory of FG (Dik, 1997a: $\S 4.4)$ when a term is inserted in its argument position(s).

3. Consideration of the wider discourse context in which the clause is to be inserted will enable the anaphor's now quite specific indexical character to match the properties of an appropriate referent. I will list some of the relevant factors which impinge on this final stage of the resolution process here:

(i) The relative topic status of potentially matching discourse referents;

(ii) The type of discourse connection between the anaphoric clause and the segment in which the candidate discourse referents were last evoked; 
(iii) The existence or non-existence of purely syntactic conditions relating the two clauses, conditions which may rule in or rule out certain matching processes $^{11}$;

(iv) The discourse status of the anaphoric clause in relation to the one where a candidate referent was last evoked: that is, whether the former clause is part of a background or a foreground segment, or effects a "return pop" over an intervening background segment to a previously active foreground segment which it now continues, and so on. As an illustration, consider the interpretation of the pronouns in the last sentence of the following attested extract:

...He [Kenny Rogers] grew up with four brothers and three sisters, the son of a labourer and a cleaning lady, in a poor area of Houston, Texas. "My father was an alcoholic, but it wasn't disruptive because he was a wonderful man with a great sense of humour. The worst he did for our family was use money for alcohol rather than food or clothes. But he earned it, and had the right to get something out of life. He didn't drink for the last four years." His parents were not keen on him being a musician, and the early years were tough..." (Interview with Kenny Rogers, The Radio Times, 7-13.8.99, p. 18).

Observe, first, that there are two discourse segments ${ }^{12}$ in this extract, an "outer" or containing segment where it is the journalist who conducted the interview who is the speaker (or "locutionary source"), and an inner, embedded segment corresponding to the direct speech section, where it is the interviewee, Kenny Rogers, who takes on the role of locutionary source. The direct-speech segment is explicitly delimited graphically via the opening and closing of the inverted commas, and via the switch from third-person to first-person pronouns in reference to the interviewee. Note also that the local discourse topics of each segment are distinct: for the main discourse segment, this is 'Kenny Rogers', whereas for the embedded discourse segment, it is 'Kenny Rogers' father'. Once the direct-speech segment is terminated, it is "popped" from the highest position in the "focus stack" (according to Grosz \& Sidner's 1986 hierarchy of "focus spaces" associated with given discourse segments), and its contents are therefore no longer available for anaphors (here the possessive determiner his and the third-person pronoun him in the final sentence) to pick up. And this corresponds to intuition, since these two anaphors are unambiguous in referring to Kenny Rogers, rather than to KR's father, the topic of the intervening direct-speech segment. This is also an instance where the criterion specified in 3(i) comes into play (i.e. anaphors' sensitivity to topicality differences in their

11 See in particular Van Hoek (1997) for a functionally-oriented account of the traditionally syntactically-defined constraints regulating intra-clausal anaphora. Van Hoek's work is framed within Langacker's Cognitive Grammar system, an approach which has much in common with FG.

12 That is, basic discourse units, defined in part by their implementing a particular discourse purpose or goal relative to some more global discourse purpose: see Grosz \& Sidner (1986) for both the term discourse segment and its definition and illustration. 
potential referents). These anaphors, in conjunction with the content of their host predicator and the closing of the inverted commas at the end of the immediately preceding sentence, effect a "return pop" to the main, interrupted segment, which is about Kenny Rogers himself.

Using (17) as a source of data for various other types of anaphor (specifically, the predicational it in line 3, and the first-order it in line 5, in addition to the instances of he and that of $\phi$ within the embedded, direct-speech segment), we can illustrate how the various types of resolution heuristics specified above operate. Taking first the it in line 3, this is the subject (and, more to the point, "external" argument - $\mathrm{A}^{1}$ in FG terms) of the adjectival predication "not (be disruptive)"; as such, its denotation type would be that of a 'second-order' entity, a type which is compatible with the range of entity-types denotable by this pronoun (as (16) indicates). Consideration of the wider discourse context yields the property "being an alcoholic", which has just been asserted of the local discourse topic of the segment being developed (Kenny Rogers' father). Now, this property can be construed in one of two ways: either as an attribute (the property "being an alcoholic" qua property), thus a zero-order entity; or as a dynamic SoA having a duration, localisation in time and space, and so on. Interestingly, it is the imposition of a second-order entity denotation type by the predicator (be) disruptive which selects the second of these two interpretation types from within this potential antecedent. Such a matching (the reference of it and the dynamically-construed property in question) yields a perfectly coherent predication when combined with the negated adjectival predication (NEG $\mathrm{X}_{\mathrm{i}}:\left(\mathrm{PAST} \mathrm{e}_{\mathrm{i}}\right.$ : \{disruptive $\left._{\mathrm{Adj}}\right\}\left(\mathrm{d}_{1} \mathrm{Ae}_{\mathrm{j}}\right.$ :<inanimate $\left.\left.\left.>\left(\mathrm{e}_{\mathrm{j}}\right)\right)_{\varnothing}\left(\mathrm{e}_{\mathrm{i}}\right)\right)\left(\mathrm{X}_{\mathrm{i}}\right)\right)$.

Moreover, the property applied to Kenny Rogers' father of being an alcoholic is part of the focus space which is active at the point when the clause ...but it wasn't disruptive is processed, so that the pronoun it, which is specialized in accessing high-focus referents (see Gundel et al.'s, 1993, "Givennness Hierarchy"), may readily retrieve it.

The next occurrence of the pronoun it is found in line 5 in the clause But he earned it... Here, the pronoun is the direct object (i.e. $\mathrm{A}^{2}$ ) of the verbal predicate earn, so that it is construed as denoting a first-order entity, more specifically (due to the sense of earn), a definite amount of money. Again, a referent specifically concerning 'money' has very recently been evoked (in the immediately preceding sentence), and so forms part of the focus space which is inherited by its following predication (through the connection effected via the conjunction but, and the occurrence of a pronoun, as subject of the verb, which maintains the previously existing topic, 'Kenny Rogers' father'). For these reasons, this second occurrence of the pronoun it is interpreted as 'the money which KR's father used to buy alcohol', and not 'the alcohol which KR's father 
used [the] money [which he earned] to buy', which out of context is a type of referent which, potentially, this pronoun may well have.

These assignments of referents to pronouns within a naturally-occurring text demonstrate the crucial role in this process played by the predicator of the indexical predication, through its transferring to the anaphor a specific selectional constraint which will enable it to retrieve a suitable part of the currently existing discourse representation as its referent. But this retrieval is by no means a direct, deterministic procedure, for as we have seen, the anaphor concerned, in conjunction with its immediate discourse-predicational context, is responsible for altering, adapting that salient discourse representation in relation to its new context.

This brief discussion has also shown that anaphora does not involve a relation between an anaphor and the referent of its antecedent(-trigger) (in my terminology), but between an anaphor and the result of the processing of the relevant textual segment containing that trigger: in the case of the first it analysed above, the pronoun is not interpreted as equivalent to simply 'being alcoholic' qua general concept, but to 'KR's father's being alcoholic during the period when KR and his brothers and sisters grew up'; likewise, the second instance of $i t$ which we examined is not interpreted as referring in general terms to 'money', but to 'the money which KR's father used to buy alcohol', a much more specific referent. These referents are not available at the level of text, but at that of discourse (see my earlier distinction between these two notions under (1) in section 2); thus, in order to deal satisfactorily with discourse anaphora, more than simply the textual record of a communicative act needs to be taken into account - in particular also, a discourse model, where the results of the earlier processing of textual segments relative to a given context and their integration need to be available as the further context in terms of which subsequent textual segments are processed.

\section{Conclusion}

There should be a much greater "division of labour" in the FG account of discourse anaphora, as between the concerns of underlying clause structure (the representation of anaphoric terms as well as of the relevant properties of the anaphoric clause as a whole), and the broader discourse context in which the anaphoric predication is set. It is this dialectical relation between bottom-up and top-down processes which is instrumental in resolving an anaphor's reference - but also in specifying its precise function within the structure of the discourse as a whole. 'Prior mention' as a condition for the existence of discourse anaphora has, I believe, no specific role as such to play in an account of this phenomenon. Instead, the more general notion of "antecedent trigger" is, I would argue, required in order to bring exophora as well as indirect (e.g. "associative") anaphora within the purview of this device. 
More elaborate specification of the various anaphor types (along the lines I have suggested in (16)) should be undertaken, and the semantic-pragmatic effects on a given anaphor of the composition of the elements making up the anaphoric predication need to be made explicit. Furthermore, work needs to be done on the representation of discourse referents within a discourse model, taking account of discourse-dynamic relations such as coherence relations among clauses, discourse topic structures and hierarchical discourse segmentation. I have attempted this for a selection of naturally occurring data using Asher's (1993) Segmented Discourse Representation Theory format in my recent book (1999: § 5.4.3). ${ }^{13}$

The picture painted above does, I believe, make for a more complete and more realistic view of the complex domain of discourse anaphora than the (necessarily) programmatic account given by Dik (1997b) in chapter 10.

\section{References}

Asher, N. (1993) Reference to Abstract Objects in Discourse, Dordrecht: Kluwer Academic Publishers.

Asher, N., \& Wada, H. (1988) 'A computational account of syntactic, semantic and discourse principles for anaphora resolution', Journal of Semantics $6(3 / 4): 309-344$.

Connolly, J. H., Vismans, R.M., Butler, C. S., \& Gatward, R.A. (eds.) (1997) Discourse and Pragmatics in Functional Grammar, Berlin/New York: Mouton de-Gruyter.

Cornish, F. (1992) 'So be it: the discourse-semantic roles of so and it', Journal of Semantics 9: 163-178.

Cornish, F. (1997) 'Non-standard anaphora, discourse integration, and coherence', Verbum XIX (1-2): 5-23.

Cornish, F. (1998) 'Les "chaînes topicales" : leur rôle dans la gestion et la structuration du discours', Cahiers de Grammaire 23: 19-40.

Cornish, F. (1999) Anaphora, Discourse, and Understanding. Evidence from English and French, Oxford: Clarendon Press.

Dik, S.C. (1997a) The Theory of Functional Grammar, Part 1: The structure of the clause, 2nd edition, Berlin \& New York: Mouton de Gruyter.

Dik, S.C. (1997b)The Theory of Functional Grammar, Part 2: Complex and derived constructions, Berlin \& New York: Mouton de Gruyter.

Fretheim, T. \& Gundel, J.K. (eds.) (1996) Reference and Referent Accessibility, Amsterdam \& Philadelphia : John Benjamins.

Grosz, B.J., \& Sidner, C.L. (1986) 'Attention, intentions, and the structure of discourse', Computational Linguistics 12: 175-204.

13 I believe SDRT to be broadly compatible with the developing FG clause-structure framework. 
Gundel, J.K., Hedberg, N., \& Zacharski, R. (1993) 'Cognitive status and the form of referring expressions in discourse',Language 69 (2): 274-307.

Hannay, M., \& Bolkestein, A.M. (eds.) (1998) Functional Grammar and Verbal Interaction, Amsterdam/Philadelphia: John Benjamins.

Hengeveld. K. (2000) 'The architecture of a Functional Discourse Grammar', unpublished paper, Dept. of Linguistics, University of Amsterdam.

Lambrecht, K. (1994) Information Structure and Sentence Form. Topic,

focus, and the mental representations of discourse referents, Cambridge: Cambridge University Press.

Liedtke, F. (1998) 'Illocution and grammar: a double-level approach', in Hannay \& Bolkestein (eds.), 107-127.

Mackenzie, J. L. (1992) 'Places and things'. In M. Fortescue, P. Harder $\&$ L. Kristoffersen (eds.), Layered Structure and Reference in a Functional Perspective, Amsterdam/Philadelphia: John Benjamins, 253276.

McCawley, J.D. (1991) A Linguistic Flea Circus, Bloomington, Indiana: Indiana University Lingistics Club mimeo.

Oakhill, J., \& Garnham, A. (1992) 'Linguistic prescriptions and anaphoric reality', Text 12: 161-182.

Pustejovsky, J. (1995) The Generative Lexicon, Cambridge, Mass./London: MIT Press.

Van den Berg, M. (1998) 'An outline of a pragmatic functional grammar', in Hannay \& Bolkestein (eds.), 77-103.

Van Hoek, K. (1997) Anaphora and Conceptual Structure, Chicago: University of Chicago Press.

Walker, M.A. (1998) 'Centering, anaphora resolution, and discourse structure', ch. 19 in Walker, M.A., Joshi, A.K., \& Prince, E.F. (eds.), Centering Theory in Discourse, Oxford: Clarendon Press, 401-435.

Werth, P.N. (1999) Text Worlds: representing conceptual space in discourse, Harlow: Pearson Education Ltd. (Longman).

Wilson, D. (1992) 'Relevance and reference', University College London Working Papers in Linguistics, 1-25.

\footnotetext{
${ }^{1}$ This article is an expanded and revised version of a paper presented at the 8th International Conference on Functional Grammar which took place from 6 to 9 July 1998 at the Vrije Universiteit, Amsterdam. A slightly reduced version appeared under the title 'The Functional Grammar conception of discourse anaphora: a (constructive) critique' as Working Paper in Functional Grammar n ${ }^{\circ}$ 73, September 2000 (pp. 1-17).

${ }^{2}$ Witness the lengthy chapter 18 in vol 2 of the revised theory (Dik, 1997b), and the variety of work now being done on discourse-related issues - as represented in the conference at which the paper forming the basis of this article was presented. See also the range of interesting work within FG on issues connected with discourse contained in Connolly et al. (eds.) (1997), and in Hannay \& Bolkestein (eds.) (1998). Following the recent 9th International Conference on Functional Grammar held in Madrid from 20 to 23 September 2000, the outline of a new development in the model proper is being elaborated, to be called Functional Discourse Grammar (see Hengeveld, 2000).
} 
I quote from Werth (1999: 46): "Let me at this point redraw the distinction I drew earlier [...] between the terms 'text' and 'discourse', based on context. Thus a text consists of the language itself, without taking into account the surrounding context. A discourse, however, is a language event: it is the language together with the context which supports it." ; and p. 302 (note the phrasing): "Analysing the discourse of which [example] (6) is the textual expression,..." (my emphases within the latter quotation - FC). However, Werth does not include under the heading text the non-verbal features I include under it (see the text above), and does not consider a purely non-verbal act of communication (e.g. one conducted exclusively by means of gestures) as discourse, whereas I do. 